\title{
Theoretical work on magnetocaloric effect in $\mathrm{La}_{0.75} \mathrm{Ca}_{0.25} \mathrm{MnO}_{3}$
}

\author{
Mahmoud Aly HAMAD* \\ Physics Department, College of Science, Al-Jouf University, Al-Jouf, Skaka, P.O. Box 2014, Saudi Arabia
}

Received: September 26, 2012; Revised: November 10, 2012; Accepted: November 12, 2012

CThe Author(s) 2012. This article is published with open access at Springerlink.com

\begin{abstract}
In this work, a phenomenological model is applied to describe the magnetocaloric effect for the $\mathrm{La}_{0.75} \mathrm{Ca}_{0.25} \mathrm{MnO}_{3}$ system near a second-order phase transition from a ferromagnetic to a paramagnetic state. Based on this model, it can predict the values of the magnetocaloric properties from calculation of magnetization as a function of temperature under different external magnetic fields. The magnetic entropy change reaches a peak of about $5.39 \mathrm{~J} /(\mathrm{kg} \cdot \mathrm{K})$ at $257 \mathrm{~K}$ upon $4 \mathrm{~T}$ applied field variation. The $\Delta S_{\mathrm{M}}$ distribution is much more uniform than that of gadolinium, which is desirable for an Ericson-cycle magnetic refrigerator.
\end{abstract}

Key words: magnetocaloric effect; model; magnetic entropy change; heat capacity change; relative cooling power

\section{Introduction}

Recently, the development of new refrigeration technology, based upon the magnetocaloric effect (MCE) or electrocaloric effect, has brought an alternative to the conventional gas compression technique [1-9]. This refrigeration provides an efficient and environment-friendly solution for cooling. It is more efficient, inexpensive, and environmentally friendly for replacing the current refrigerators using greenhouse gases that are harmful to environment and contributing to global warming.

Perovskite manganites have attracted significant attention since the discovery of colossal magnetoresistance, and a large number of interesting properties of these compounds have been found. In

* Corresponding author.

E-mail: m_hamad76@yahoo.com recent years, there has been an increasing interest in using manganites not only as a material having colossal magnetoresistivity but also as a material with interesting magnetocaloric properties [9-11].

Perovskite-like manganites $\mathrm{La}_{1-x} \mathrm{Ca}_{x} \mathrm{MnO}_{3}$ exhibit a variety of physical properties depending on the $\mathrm{Ca}$ concentration $x$. The strong correlation among magnetic, electronic, orbital and transport properties of manganites makes these systems particularly sensitive to external perturbations, such as temperature variation, application of magnetic field or high pressure $[12,13]$. Characterization and application of the magnetic properties of ferromagnetic materials become increasingly important as magnetoelectronic devices for the level reliability $[14,15]$.

This paper is about theoretical work on magnetization versus temperature in different magnetic fields for the $\mathrm{La}_{0.75} \mathrm{Ca}_{0.25} \mathrm{MnO}_{3}$. It used phenomenological model for simulation of magnetization dependence on temperature variation to 
investigate magnetocaloric properties, such as magnetic entropy change, heat capacity change, temperature change and relative cooling power.

\section{Theoretical considerations}

According to phenomenological model [16], the dependence of magnetization on variation of temperature and Curie temperature $T_{\mathrm{C}}$ is presented by

$$
M=\left(\frac{M_{i}-M_{f}}{2}\right) \tanh \left[A\left(T_{\mathrm{C}}-T\right)\right]+B T+C
$$

where $M_{i}$ is an initial value of magnetization at ferromagnetic-paramagnetic transition and $M_{f}$ is a final value of magnetization at ferromagneticparamagnetic transition as shown in Fig. 1. Besides,

$$
A=\frac{2\left(B-S_{\mathrm{C}}\right)}{M_{i}-M_{f}}
$$

$B$ is magnetization sensitivity $\frac{\mathrm{d} M}{\mathrm{~d} T}$ at ferromagnetic state before transition, $S_{\mathrm{C}}$ is magnetization sensitivity $\frac{\mathrm{d} M}{\mathrm{~d} T}$ at Curie temperature $T_{\mathrm{C}}$ and

$$
C=\left(\frac{M_{i}+M_{f}}{2}\right)-B T_{\mathrm{C}}
$$

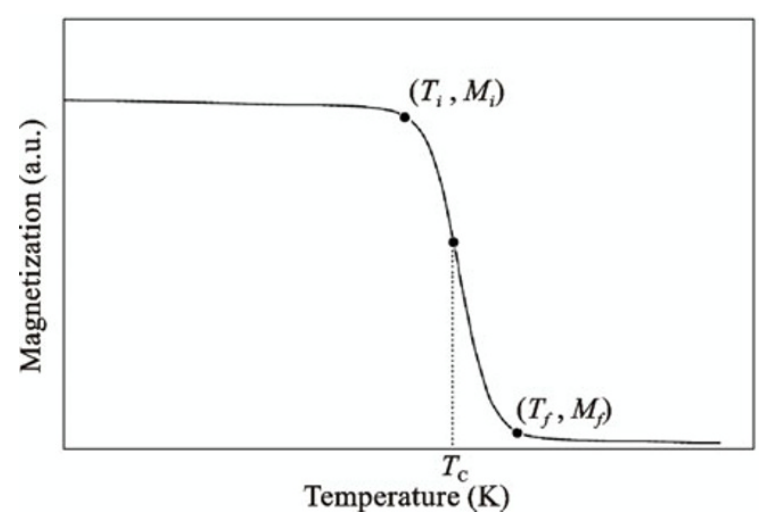

Fig. 1 Dependence of magnetization as a function of temperature.

Figure 1 shows the curve temperature dependence of magnetization in constant applied field was retraced by Eq. (1). Equation (1) is determined by the physical mechanism that the magnetic moments can be increased by decreasing temperature. At temperatures well below Curie point, the electronic magnetic moments of a ferromagnetic specimen are essentially all lined up, when regarded on a microscopic scale.
A magnetic entropy change of a magnetic system under adiabatic magnetic field variation from 0 to final value $H_{\max }$ is available by

$$
\Delta S_{\mathrm{M}}=\left\{-A\left(\frac{M_{i}-M_{f}}{2}\right) \operatorname{sech}^{2}\left[A\left(T_{\mathrm{C}}-T\right)\right]+B\right\} H_{\max }
$$

The foundation of large magnetic entropy change is attributed to high magnetic moment and rapid change of magnetization at $T_{\mathrm{C}}$. A result of Eq. (2) is a maximum magnetic entropy change $\Delta S_{\max }$ (where $T=T_{\mathrm{C}}$ ), and can be evaluated as the following equation

$$
\Delta S_{\max }=\left[-A\left(\frac{M_{i}-M_{f}}{2}\right)+B\right] H_{\max }
$$

Equation (3) is important for taking into consideration the value of the magnetic entropy change to evaluate magnetic cooling efficiency with its full-width at half-maximum.

A determination of full-width at half-maximum $\delta T_{\text {FWHM }}$ can be carried out as

$$
\delta T_{\mathrm{FWHM}}=\frac{2}{A} \operatorname{sech}\left[\sqrt{\frac{2 A\left(M_{i}-M_{f}\right)}{A\left(M_{i}-M_{f}\right)+2 B}}\right]
$$

This equation gives a full-width at half-maximum magnetic entropy change contributing for estimation of magnetic cooling efficiency as follows.

A magnetic cooling efficiency is estimated by considering magnitude of magnetic entropy change $\Delta S_{\mathrm{M}}$ and its full-width at half-maximum ( $\left.\delta T_{\mathrm{FWHM}}\right)$ [17]. A product of $-\Delta S_{\max }$ and $\delta T_{\mathrm{FWHM}}$ is called relative cooling power (RCP) based on magnetic entropy change.

$$
\begin{aligned}
& \mathrm{RCP}=-\Delta S_{\mathrm{M}}\left(T, H_{\max }\right) \times \delta T_{\mathrm{FWHM}}= \\
& \left(M_{i}-M_{f}-2 \frac{B}{A}\right) H_{\text {max }} \times \operatorname{sech}\left[\sqrt{\frac{2 A\left(M_{i}-M_{f}\right)}{A\left(M_{i}-M_{f}\right)+2 B}}\right]
\end{aligned}
$$

The magnetization-related change of the specific heat is given by [18],

$$
\Delta C_{P, H}=T \frac{\delta \Delta S_{\mathrm{M}}}{\delta T}
$$

According to this model [16], $\Delta C_{P, H}$ can be rewritten as

$$
\begin{aligned}
\Delta C_{P, H}= & -T A^{2}\left(M_{i}-M_{f}\right) \\
& \cdot \operatorname{sech}^{2}\left[A\left(T_{\mathrm{C}}-T\right)\right] \tanh \left[A\left(T_{\mathrm{C}}-T\right)\right] H_{\max }
\end{aligned}
$$


A temperature change of a magnetic system under adiabatic magnetic field variation from 0 to $H_{\max }$ can be written in the form

$$
\begin{aligned}
\Delta T & =-\frac{T}{C_{P}} \int_{0}^{H_{\max }}\left(\frac{\partial M}{\partial T}\right)_{E} \mathrm{~d} H \\
& =\frac{A T\left(M_{i}-M_{f}\right)}{2 C_{P}}\left\{\operatorname{sech}^{2}\left[A\left(T_{\mathrm{C}}-T\right)\right]+B\right\} H_{\text {max }}
\end{aligned}
$$

where $\mathrm{C}_{P}$ is the heat capacity.

From this phenomenological model, it can easily assess the values of $\delta T_{\text {FWHM }},|\Delta S|_{\max }, \mathrm{RCP}$ and $\Delta T$ for $\mathrm{La}_{0.75} \mathrm{Ca}_{0.25} \mathrm{MnO}_{3}$ under magnetic field variation.

\section{Simulation}

In order to apply phenomenological model, parameters versus $\Delta H$ are determined as displayed in Table 1. They are obtained from experimental data. A heat capacity $C_{P}=525 \mathrm{~J} /(\mathrm{kg} \cdot \mathrm{K}) \quad[19]$. Figure 2 shows magnetization versus temperature in different applied magnetic fields for $\mathrm{La}_{0.75} \mathrm{Ca}_{0.25} \mathrm{MnO}_{3}$. The symbols represent experimental data from Reference [14] while the dashed curves represent modelled data using Eq. (1). It is seen that for the given parameters, the results of calculation are in a good agreement with the experimental results. Furthermore, Figs. 3-5 show predicted values for change of magnetic entropy, specific heat and temperature respectively versus temperature. The behavior of magnetic entropy change curves suggests how to extend the range of temperatures for use in the MCE. The values of maximum magnetic entropy change, full-width at half-maximum and relative cooling power at different magnetic fields for $\mathrm{La}_{0.75} \mathrm{Ca}_{0.25} \mathrm{MnO}_{3}$ are calculated by using Eqs. (3)-(5) respectively, and tabulated in Table 2. Moreover, the maximum and minimum values of specific heat change for each sample are determined from Fig. 4.

Both $\Delta S_{\mathrm{M}}$ and $\Delta T$ reflect a fundamental importance on the understanding of the behavior of the MCE, and these terms can be approximately estimated using Eqs. (2) and (8) respectively. As shown in Fig. 3, $\Delta S_{\mathrm{M}}$ reaches a peak of about $5.39 \mathrm{~J} /(\mathrm{kg} \cdot \mathrm{K})$ at $257 \mathrm{~K}$ upon $4 \mathrm{~T}$ applied field variation. Though the maximum $\Delta S_{\mathrm{M}}$ is $9 \mathrm{~J} /(\mathrm{kg} \cdot \mathrm{K})$ upon $4 \mathrm{~T}$ applied field variation which is about $60 \%$ of that of a pure $\mathrm{Gd}$ metal $2.8 \mathrm{~J} /(\mathrm{kg} \cdot \mathrm{K})$ upon $4 \mathrm{~T}$, the $\Delta S_{\mathrm{M}}$ distribution of the $\mathrm{La}_{0.75} \mathrm{Ca}_{0.25} \mathrm{MnO}_{3}$ is much more uniform than that of gadolinium [20-22]. This feature is desirable for an Ericson-cycle magnetic refrigerator [23]. Moreover, if further increasing the magnetic field applied on the $\mathrm{La}_{0.75} \mathrm{Ca}_{0.25} \mathrm{MnO}_{3}$, it is expected that it could get better magnetocaloric effect. Furthermore, $\quad \mathrm{La}_{0.75} \mathrm{Ca}_{0.25} \mathrm{MnO}_{3}$ has better magnetocaloric effect than the same system at other level of $\mathrm{Ca}$ concentration as shown in Table 2.

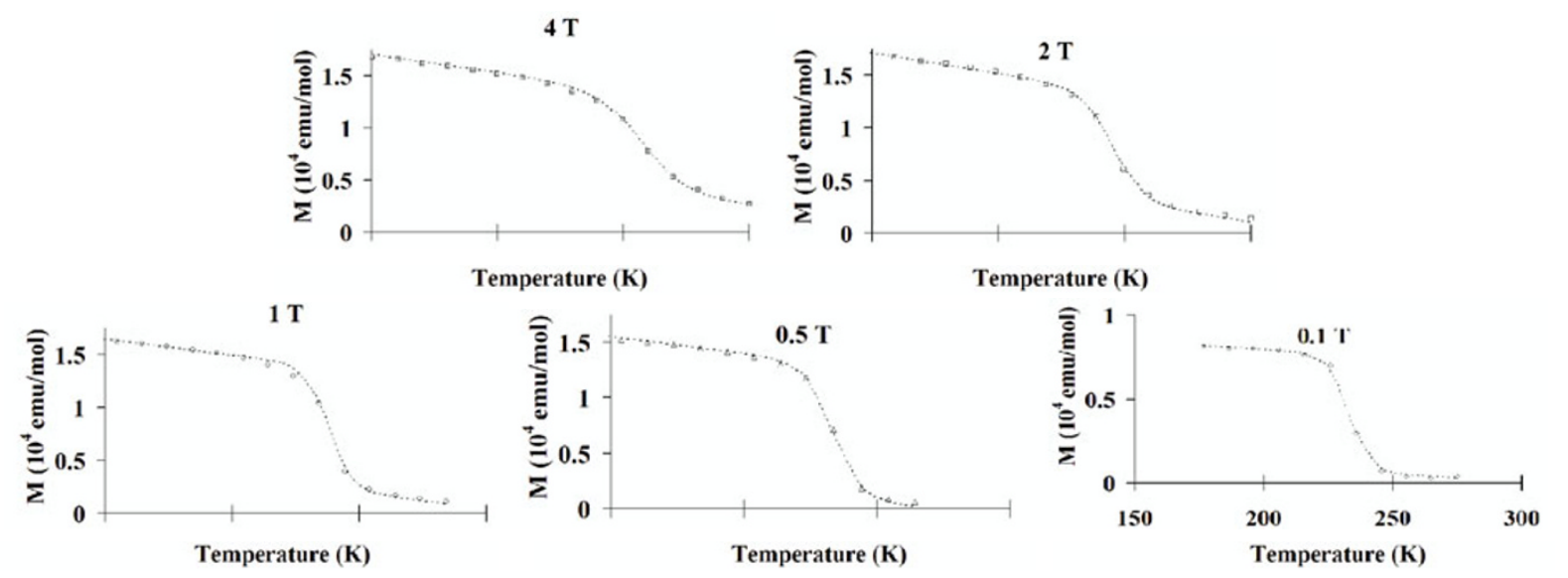

Fig. 2 Magnetization in different applied magnetic fields for the $\mathrm{La}_{0.75} \mathrm{Ca}_{0.25} \mathrm{MnO}_{3}$ versus temperature. The dashed curves are modelled results and symbols represent experimental data from Reference [14].

Table 1 Model parameters for $\mathrm{La}_{0.75} \mathrm{Ca}_{0.25} \mathrm{MnO}_{3}$ in different applied magnetic fields

\begin{tabular}{cccccc}
\hline$H(\mathrm{~T})$ & $M_{i}\left(10^{4} \mathrm{emu} / \mathrm{mol}\right)$ & $M_{f}\left(10^{4} \mathrm{emu} / \mathrm{mol}\right)$ & $T_{\mathrm{C}}(\mathrm{K})$ & $B\left(10^{4} \mathrm{emu} /(\mathrm{mol} \cdot \mathrm{K})\right)$ & $S_{\mathrm{C}}\left(10^{4} \mathrm{emu} /(\mathrm{mol} \cdot \mathrm{K})\right)$ \\
\hline 0.1 & 0.76 & 0.07 & 233 & -0.0010 & -0.043 \\
0.5 & 1.30 & 0.11 & 233 & -0.0030 & -0.059 \\
1.0 & 1.38 & 0.23 & 238 & -0.0030 & -0.066 \\
2.0 & 1.34 & 0.32 & 245 & -0.0039 & -0.046 \\
4.0 & 1.33 & 0.41 & 257 & -0.0035 & -0.030 \\
\hline
\end{tabular}


Table 2 The predicted values of applied magnetocaloric properties for $\mathrm{La}_{0.75} \mathrm{Ca}_{0.25} \mathrm{MnO}_{3}$ and other compositions in different applied magnetic fields

\begin{tabular}{|c|c|c|c|c|c|c|c|c|}
\hline Composition & $\begin{array}{l}\Delta H \\
(\mathrm{~T})\end{array}$ & $\begin{array}{c}-\Delta S_{\max } \\
(\mathrm{J} /(\mathrm{kg} \cdot \mathrm{K}))\end{array}$ & $\begin{array}{c}\delta T_{\mathrm{FWHM}} \\
(\mathrm{K})\end{array}$ & $\begin{array}{c}\text { RCP } \\
(\mathrm{J} / \mathrm{kg})\end{array}$ & $\begin{array}{l}\Delta C_{P, H(\max )} \\
(\mathrm{J} /(\mathrm{kg} \cdot \mathrm{K}))\end{array}$ & $\begin{array}{l}-\Delta C_{P, H(\min )} \\
(\mathrm{J} /(\mathrm{kg} \cdot \mathrm{K}))\end{array}$ & $\begin{array}{c}|\Delta T|_{\max } \\
(\mathrm{K})\end{array}$ & Reference \\
\hline \multirow{5}{*}{$\mathrm{La}_{0.75} \mathrm{Ca}_{0.25} \mathrm{MnO}_{3}$} & 0.1 & 0.18 & 14.76 & 2.61 & 4.29 & -4.11 & 0.09 & This work \\
\hline & 0.5 & 1.36 & 19.55 & 26.50 & 22.42 & -21.11 & 0.60 & This work \\
\hline & 1.0 & 2.52 & 16.71 & 42.19 & 59.71 & -56.77 & 1.38 & This work \\
\hline & 2.0 & 3.75 & 22.98 & 86.12 & 62.34 & -58.40 & 1.97 & This work \\
\hline & 4.0 & 5.39 & 33.97 & 183.16 & 58.11 & -53.19 & 2.71 & This work \\
\hline $\mathrm{La}_{0.70} \mathrm{Ca}_{0.30} \mathrm{MnO}_{3}$ & 1.0 & $1.38,1.95$ & - & 41,49 & - & - & - & [17] \\
\hline $\mathrm{La}_{0.67} \mathrm{Ca}_{0.33} \mathrm{MnO}_{3}$ & 3.0 & 2.60 & - & 114 & - & - & - & [17] \\
\hline $\mathrm{La}_{0.55} \mathrm{Ca}_{0.45} \mathrm{MnO}_{3}$ & 1.5 & 1.90 & - & 68 & - & - & - & [17] \\
\hline
\end{tabular}

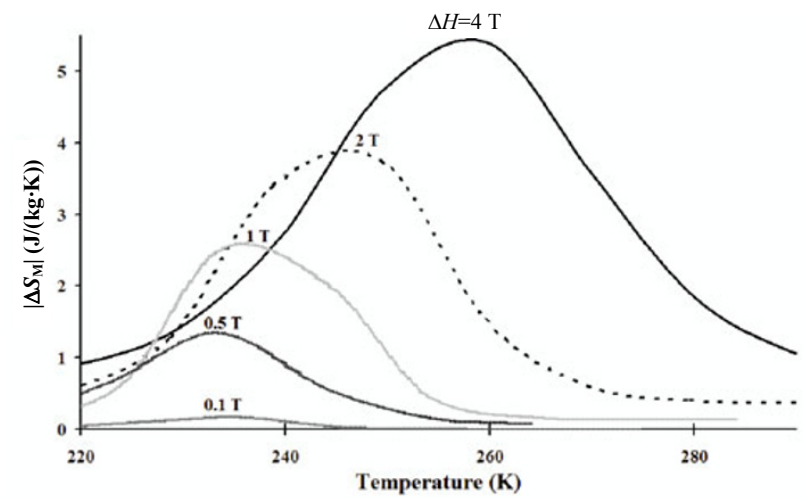

Fig. 3 Magnetic entropy change as function of temperature for $\mathrm{La}_{0.75} \mathrm{Ca}_{0.25} \mathrm{MnO}_{3}$ in different applied magnetic field variations.

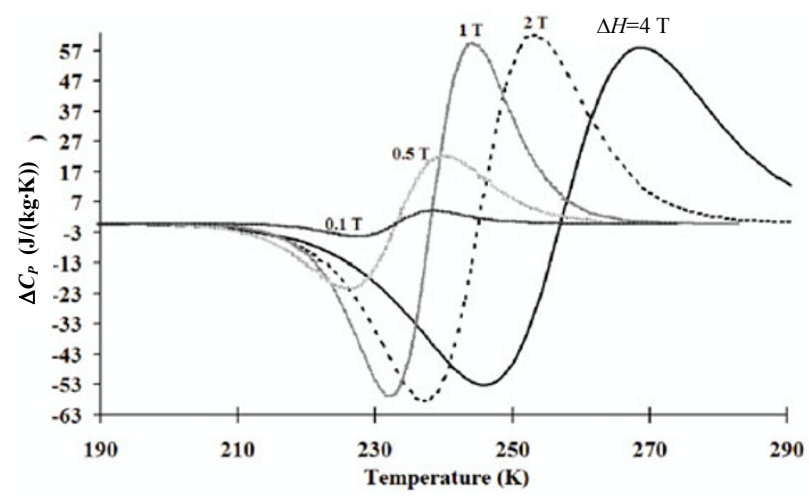

Fig. 4 Heat capacity changes as function of temperature for $\mathrm{La}_{0.75} \mathrm{Ca}_{0.25} \mathrm{MnO}_{3}$ in different applied magnetic field variations.

In general, the large magnetic entropy change in perovskite manganites has been believed to be related to the considerable variation of magnetization near $T_{\mathrm{C}}$ [24]. The spin-lattice coupling in the magnetic ordering process could play a significant role in additional magnetic entropy change [25].

Magnetic refrigeration works because there are two contributions to the total entropy of the system: a magnetic entropy that is related to the order of

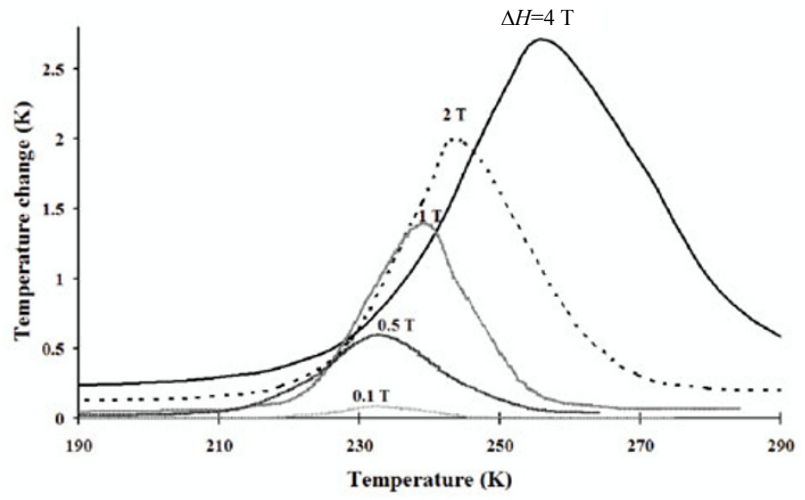

Fig. 5 Temperature changes as function of temperature for $\mathrm{La}_{0.75} \mathrm{Ca}_{0.25} \mathrm{MnO}_{3}$ in different applied magnetic field variations.

magnetic moments, and a lattice entropy that is related to the temperature. It is convenient to start with a material with disordered magnetic moments, which is typically found with the lowest field magnitude and ambient temperature within the refrigeration cycle. Applying a magnetic field adiabatically causes the spins in the material to align. Recalling that no heat is exchanged in an adiabatic process, the decrease in magnetic entropy must be compensated by an increase in the lattice entropy, which implies that the material must heat up. Once the moments are aligned and excess heat has been removed, the material returns to ambient temperature. The adiabatic removal of the applied field then leads to an increase in magnetic entropy, which is compensated for by a decrease in the lattice entropy, and thus the temperature of the material decreases below ambient.

Due to strong coupling between spin and lattice, significant lattice change accompanying magnetic transition in perovskite manganites has been observed $[26,27]$. The lattice structural change in the $\mathrm{Mn}-\mathrm{O}$ bond distance as well as Mn-O-Mn bond angle would, in turn, favor the spin ordering. Thereby, a more abrupt 
reduction of magnetization near $T_{\mathrm{C}}$ occurs and results in a significant magnetic-entropy change [28-30]. In this way, a conclusion might be drawn that a strong spin-lattice coupling in the magnetic transition process would lead to additional magnetic entropy change near $T_{\mathrm{C}}$, and consequently, favors the MCE.

\section{Conclusion}

Dependence of the magnetization on temperature variation for $\mathrm{La}_{0.75} \mathrm{Ca}_{0.25} \mathrm{MnO}_{3}$ upon different magnetic fields was simulated. In general, this allows predicting the magnetocaloric properties of $\mathrm{La}_{0.75} \mathrm{Ca}_{0.25} \mathrm{MnO}_{3}$ such as magnetic entropy change, full-width at half-maximum, relative cooling power and magnetic specific heat change for $\mathrm{La}_{0.75} \mathrm{Ca}_{0.25} \mathrm{MnO}_{3}$ upon different magnetic field variations. Though the maximum $\Delta S_{\mathrm{M}}$ is about $60 \%$ of that of gadolinium, the $\Delta S_{\mathrm{M}}$ distribution is much more uniform than that of gadolinium, which is desirable for an Ericson-cycle magnetic refrigerator and household application of active magnetic refrigerant materials.

\section{References}

[1] de Oliveira A, von Ranke PJ. Theoretical aspects of themagnetocaloric effect. Phys Reports 2010, 489: 89.

[2] Gschneidner KA, Pecharsky VK, Tsoko AO. Recent developments in magnetocaloric materials. Rep Prog Phys 2005, 68: 1479.

[3] Hamad MA. Detecting giant electrocaloric effect in $\mathrm{Sr}_{x} \mathrm{Ba}_{1-x} \mathrm{Nb}_{2} \mathrm{O}_{6}$ single crystals. Appl Phys Let 2012, 100: 192908.

[4] Hamad MA. Magnetocaloric effect in polycrystalline $\mathrm{Gd}_{1-x} \mathrm{Ca}_{x} \mathrm{BaCo}_{2} \mathrm{O}_{5.5}$. Mater Lett 2012, 82: 181-183.

[5] Hamad MA. Investigations on electrocaloric properties of [111] oriented $0.955 \mathrm{PbZn}_{1 / 3} \mathrm{Nb}_{2 / 3} \mathrm{O}_{3}$ $0.045 \mathrm{PbTiO}_{3}$ single crystals. Phase Transition 2012, DOI: 10.1080/01411594.2012.674527.

[6] Hamad MA. Magnetocaloric effect in $\mathrm{Ge}_{0.95} \mathrm{Mn}_{0.05}$ films. $J$ Supercond Nov Magn 2012, DOI: 10.1007/s10948-012-1762-3.

[7] Hamad MA. Theoretical investigations on electrocaloric properties of relaxor ferroelectric $0.9 \mathrm{PbMg}_{1 / 3} \mathrm{Nb}_{2 / 3} \mathrm{O}_{3}-0.1 \mathrm{PbTiO}_{3}$ thin film. $J$ Comput Electron 2012, 11: 344-348

[8] Hamad MA. Calculation of electrocaloric properties of ferroelectric $\mathrm{SrBi}_{2} \mathrm{Ta}_{2} \mathrm{O}_{9}$. Phase Transition 2012, 85: $159-168$.
[9] Hamad MA. Theoretical work on magnetocaloric effect in ceramic and sol-gel $\mathrm{La}_{0.67} \mathrm{Ca}_{0.33} \mathrm{MnO}_{3} . J$ Therm Anal Calorim 2012, DOI: 10.1007/s10973012-2505-1.

[10] Debnath JC, Zeng R, Kim JH, et al. Improvement of refrigerant capacity of $\mathrm{La}_{0.7} \mathrm{Ca}_{0.3} \mathrm{MnO}_{3}$ material with a few percent Co doping. J Magn Magn Mater 2011, 323: 138-143.

[11] Hamad MA. Magnetocaloric properties of $\mathrm{La}_{0.6} \mathrm{Ca}_{0.4} \mathrm{MnO}_{3}$. J Therm Anal Calorim 2012, DOI: 10.1007/s10973-012-2723-6.

[12] Baldini M, Capogna L, Capone M, et al. Pressure induced magnetic phase separation in $\mathrm{La}_{0.75} \mathrm{Ca}_{0.25} \mathrm{MnO}_{3}$ manganite. $J$ Phys: Condens Matter 2012, 24: 045601.

[13] Schiffer P, Ramirez AP, Bao W, et al. Low temperature magnetoresistance and the magnetic phase diagram of $\mathrm{La}_{1-x} \mathrm{Ca}_{x} \mathrm{MnO}_{3}$. Phys Rev Lett 1995,75: 3336-3339.

[14] Hamad MA. Prediction of energy loss of $\mathrm{Ni}_{0.58} \mathrm{Zn}_{0.42} \mathrm{Fe}_{2} \mathrm{O}_{4}$ nanocrystalline and $\mathrm{Fe}_{3} \mathrm{O}_{4}$ nanowire arrays. Jpn J Appl Phys 2010, 49: 085004.

[15] Hamad MA. Calculations on nanocrystalline $\mathrm{CoFe}_{2} \mathrm{O}_{4}$ prepared by polymeric precursor method. $J$ Supercond Nov Magn 2012, DOI: 10.1007/s10948-012-1783-y.

[16] Hamad MA. Prediction of thermomagnetic properties of $\mathrm{La}_{0.67} \mathrm{Ca}_{0.33} \mathrm{MnO}_{3}$ and $\mathrm{La}_{0.67} \mathrm{Sr}_{0.33} \mathrm{MnO}_{3}$. Phase Transitions 2012, 85: 106-112.

[17] Phan MH, SC Yu. Review of the magnetocaloric effect in manganite materials. J Magn Magn Mater 2007, 308: 325.

[18] Földeaki M, Chahine R, Bose TK. Magnetic measurements: A powerful tool in magnetic refrigerator design. $J$ Appl Phys 1995,77: 3528-3537.

[19] Terashita H, Garbe JJ, Neumeier JJ. Compositional dependence of the magnetocaloric effect in $\mathrm{La}_{1-x} \mathrm{Ca}_{x} \mathrm{MnO}_{3}(0 \leq x \leq 0.52)$. Phys Rev $B$ 2004,70: 094403.

[20] Williams DV. Characterization of the structural and magnetic properties of Gd thin films. Ph.D. Thesis. Florida (USA): University of South Florida, 2010.

[21] Goodenough JB. Theory of the role of covalence in the perovskite-type manganites $[\mathrm{La}, \mathrm{M}(\mathrm{II})] \mathrm{MnO}_{3}$. Phys Rev 1955, 100: 564.

[22] Dan'kov SY, Tishin AM, Pecharsky VK, et al. Magnetic phase transitions and the magnetothermal properties of gadolinium. Phys Rev B 1998, 57: 3478-3490.

[23] Pecharsky VK, Gschneidner KA. Magnetocaloric effect and magnetic refrigeration. J Magn Magn Mater 1999, 200: 44-56. 
[24] Bohigas X, Tejada J, del Barco E, et al. Tunable magnetocaloric effect in ceramic perovskites. Appl Phys Lett 1998, 73: 390.

[25] Guo ZB, Du YW, Zhu JS, et al. Large magnetic entropy change in perovskite-type manganese oxides. Appl Phys Lett 1997, 78: 1142-1145 .

[26] Radaelli PG, Cox DE, Marezio M, et al. Simultaneous structural, magnetic, and electronic transitions in $\mathrm{La}_{1-x} \mathrm{Ca}_{x} \mathrm{MnO}_{3}$ with $x=0.25$ and 0.50 . Phys Rev Lett 1995, 75: 4488-4491.

[27] Kim KH, Gu JY, Choi HS, et al. Frequency shifts of the internal phonon modes in $\mathrm{La}_{0.7} \mathrm{Ca}_{0.3} \mathrm{MnO}_{3}$. Phys Rev Lett 1996, 77: 1877-1880.
[28] Tang T, Gu KM, Cao QQ, et al. Magnetocaloric properties of Ag-substituted perovskite-type manganites. J Magn Magn Mater 2000, 222: 110-114.

[29] Phan MH, Tian SB, Yu SC, et al. Magnetic and magnetocaloric properties of $\mathrm{La}_{0.7} \mathrm{Ca}_{0.3-x} \mathrm{Ba}_{x} \mathrm{MnO}_{3}$ compounds. J Magn Magn Mater 2003, 256: 306-310.

[30] Sun Y, Tong W, Zhang YH. Large magnetic entropy change above $300 \mathrm{~K}$ in $\mathrm{La}_{0.67} \mathrm{Sr}_{0.33} \mathrm{Mn}_{0.9} \mathrm{Cr}_{0.1} \mathrm{O}_{3} . J$ Magn Magn Mater 2001, 232: 205-208. 